\title{
Narrative review of prognosis related communication in advanced cancer patients
}

\author{
Karam Al-Issa, Paul R. Helft \\ Department of Medicine, Division of Hematology/Oncology, Indiana University Melvin and Bren Simon Comprehensive Cancer Center, Indiana \\ University School of Medicine, Charles Warren Fairbanks Center for Medical Ethics, Indiana University Health, Indianapolis, IN, USA \\ Contributions: (I) Conception and design: Both authors; (II) Administrative support: Both authors; (III) Provision of study materials or patients: \\ Both authors; (IV) Collection and assembly of data: Both authors; (V) Data analysis and interpretation: Both authors; (VI) Manuscript writing: Both \\ authors; (VII) Final approval of manuscript: Both authors. \\ Correspondence to: Paul R. Helft, MD. Department of Medicine, Division of Hematology/Oncology, Indiana University Melvin and Bren Simon \\ Comprehensive Cancer Center, Indiana University School of Medicine, Charles Warren Fairbanks Center for Medical Ethics, Indiana University \\ Health, 535 Barnhill Dr, RT473, Indianapolis, IN 46202, USA. Email: phelft@iu.edu.
}

\begin{abstract}
Objective: In this review we will focus on doctor-patient communication as one of the most important modifiable factors which may have a significant impact especially on the important transition between the ambulatory and terminal phases of cancer.

Background High quality communication about prognosis for cancer patients is a critical component of advance care planning, and it plays a critical role among all the complex factors that affect end of life care decisions. In this review we focus on doctor-patient communication as the most important modifiable factor impacting the transitional period between the ambulatory phase and the terminal phase of cancer. We also discuss how prognostic understanding among advanced cancer patients influences decisions in regard to their cancer care.

Methods: We investigated studies that examined advanced cancer patients and prognosis-related communication.

Conclusions: We believe that oncologists' skills, experience, and comfort level in managing patients' reactions to negative information is a principal barrier that contributes substantially to the deficit of highquality prognosis-related communication described in the literature. We also believe that it is useful to categorize oncologists with regard to their ability to engage in high quality communication, and we suggest category-specific strategies to improve oncologists' skills to conduct more effective prognosis related communication with their patients.
\end{abstract}

Keywords! Prognosis; advanced cancer; communication skills

Submitted Jan 19, 2021. Accepted for publication Jun 17, 2021.

doi: 10.21037/apm-21-142

View this article at: https://dx.doi.org/10.21037/apm-21-142

\section{Introduction}

We present the following article in accordance with the Narrative Review reporting checklist (available at https:// dx.doi.org/10.21037/apm-21-142).

\section{Background}

"Prognosis" derives from a Greek word that means fore- knowing or foreseeing. In a medical context it means the prediction or estimation of the chance of recovery or survival from a specific disease. Prognosis in cancer patients can depend on several factors, such as the stage of the disease at diagnosis, type and subtype of cancer, and the molecular profile of the tumor. Communicating estimates of prognosis is one of the most important duties physicians fulfill with their patients (1). Discussing prognosis is a 
critical step in managing cancer patients, but it is often avoided during patient encounters, so oncologists may fail to raise this important topic by asking patients if they would like to hear about their prognosis or discuss it too briefly or too vaguely. Patients may avoid asking the question or request not to discuss prognosis because of fear, grief, or anxiety. Inadequate understanding of prognosis may therefore result from both oncologist- and patient-specific factors.

According to the World Health Organization, it is estimated that approximately 10 million patients die from cancer every year worldwide, while in the United States, it is estimated that 600,000 patients die from cancer every year. In Europe, cancer deaths total 1.9 million annually. Many of these patients experience lower-quality prognosis-related communication from their oncologists. The persistence of such inadequate patient-clinician communication with advanced cancer patients is highlighted in multiple studies in the literature. Such suboptimal communication leads to lower-quality end of life experiences (2,3).

Markers of lower quality end of life care include-among others-dying in the hospital, late receipt of chemotherapy, and late referral to hospice programs. Studies have suggested that $20-25 \%$ of US cancer patients are overtreated near end of life and experience low quality deaths. The intensity of cancer treatment at the end of life for many advanced cancer patients remains high (4). Studies have shown that health care use and associated expenses in the last 4 weeks of life often rise $(5,6)$.

In Medicare beneficiaries, researchers have found that $26-33 \%$ of cancer patients received chemotherapy in the last 6 months of life, $20-23 \%$ in the last 3 months of life, and $9 \%$ in the last month of life (7). This appears to occur despite the fact that both the American Society of Clinical Oncology (ASCO) and National Quality Forum (NQF) recommend less intensive therapies in the last few weeks of life for cancer patients (8-10).

On the other hand, utilization of palliative care and hospice toward the end of life remains sub-optimal. Recent studies have shown that half of patients who are referred to hospice die within 3 weeks, and $35.7 \%$ of patients die within 1 week (11). In the Medicare Payment Advisory Commission (MedPAC) March 2019 Report to Congress, it was reported that more than one-quarter of hospice decedents enroll in hospice in the last week of life, a length of stay that is commonly thought to be of less benefit to patients than enrolling earlier (12).

Even though the causes of over treatment of cancer patients toward the end of life are complicated, multiple lines of evidence have found a correlation between better prognostic understanding and preferences for less intensive treatment at the end of life, suggesting that higher quality prognosis-related communication may contribute to patients' choices and receipt of higher quality care close to death $(11,13)$. Poor quality communication can therefore lead to poor clinical outcomes. However, it can also affect patients ethically and psychologically, since cancer patients deserve to understand their prognosis in order to make considered decisions within the framework of their values and preferences.

\section{Prognosis related communication among advanced cancer patients}

Evidence has long existed to support the idea that understanding of disease prognosis affects treatment choices. Many trials have shown that patients are more willing to avoid aggressive treatment interventions when they better understand their poor prognosis $(14,15)$.

The degree to which oncologists engage in prognosis related communication appears to be variable. In one large study of cancer patients on palliative chemotherapy, only $39 \%$ of patients reported that prognosis was discussed by medical oncologists (16). Other studies found that physicians never discussed prognosis with families more than $50 \%$ of the time (17-20).

In addition to these observational studies, Step and Ray led a study in which they interviewed 30 female cancer patients about their encounter with prognosis discussion during initial diagnosis and at the time of recurrence (21). Study participants reported that, during initial diagnosis conversations, physicians communicated about prognosis optimistically. However, later at the time of disease recurrence, these conversations focused to a greater degree on logistics of disease management. In addition, greater uncertainty was communicated during those recurrence conversations, which led to tension-filled "prognosis dance[s]" where both doctors and patients were seeking to avoid information (21).

Similarly, when oncology nurses were surveyed about their perceptions of the quality of prognosis related communication among the oncologists with whom they work, similar patterns emerge. In a national survey of a random sample of US oncology nurses, $25.1 \%$ of nurses agreed that oncologists rarely or never kept them informed about their prognosis related communication with advanced 
cancer patients, and $72 \%$ agreed or strongly agreed that physician discomfort with giving bad news was a major barrier to helping patients and families understand their prognosis. In addition, $26.1 \%$ disagreed or strongly disagreed that physicians had skills in handling prognosis related communication. Thirty percent $(30.2 \%)$ of nurses felt that physicians rarely addressed end of life matters early in the course of disease, and $32.8 \%$ of nurses agreed on that, when patients did not seem to perceive their prognosis, it was because their doctors had not fully discussed it (3).

\section{Prognosis and therapeutic misconception}

Measured prognostic understanding among advanced cancer patients is variable, and many studies suggest that advanced cancer patients frequently report prognostic or therapeutic misconception. A review article of 37 studies in the literature showed that around $75 \%$ of advanced cancer patients reported unawareness of their poor prognosis (2). Such "prognostic misconception" has also been documented in other studies. Weeks found in a study of more than 1,000 patients with metastatic lung or colorectal cancer receiving palliative chemotherapy that $69 \%$ of lung cancer patients and $81 \%$ of colorectal cancer patients appeared not to understand that their chemotherapy was not intended to cure their cancer (22). Many other studies have found that cancer patients frequently were not aware of the intention of their treatment $(1,23,24)$.

Such prognostic and therapeutic misconception may contribute to the uptake of non-beneficial disease-directed therapy toward the end of life by inhibiting acceptance of the inevitability of impending mortality. A study by Mack et al. has shown that patients are more likely to undertake more intensive treatment at the end of life when they overestimate their prognosis $(25,26)$. Furthermore, a study by Silvestri suggested that patients with lung cancer would not have chosen to accept the anti-cancer therapy they chose if they were fully aware of their prognosis and risks and benefits of palliative chemotherapy (27). One other study examined advanced cancer patients who reported more accurate understanding of their prognosis and showed that they are less likely to agree to receive intensive therapy at end of their lives (28).

In this review we will focus on doctor-patient communication as one of the most important modifiable factors which may have a significant impact especially on the important transition between the ambulatory and terminal phases of cancer. We would like to highlight the importance of high-quality communication between cancer patients and their providers and how this can lead to better understanding of cancer prognosis, which in turn leads to better decision making during this critical period of patients' lives. We propose that the quality and/or effectiveness of communication will have meaningful downstream effects on decreasing the intensity of therapy that patients receive at the end of life.

\section{Methods}

We investigated studies that were published between 1998 and 2019, while we focused on studies that examined advanced cancer patients and prognosisrelated communication. We used the following keywords: prognosis, advanced cancer, and communication skills. Most of these studies were available in the PubMed data base. Based on this critical review, we came to hypothesize that we could classify physicians into three broad categories in regard to their communication skills. We concluded that this conceptual framework could be a useful way to understand differences in communication skills, which in turn suggests that different approaches to improving the quality of communication are needed. Table 1 presents the major studies we investigated.

\section{Discussion}

\section{Causes of lower quality prognosis related communication}

Multiple factors can lead to physicians' lower participation in prognosis-related communication, including the desire to balance efforts to sustain hope and to deliver accurate information, variable information preferences among patients, variability of information preferences over time, and inaccuracy or uncertainty of prognosis. One qualitative study examined the barriers to high-quality communication about prognosis and grouped the barriers into: (I) physicianrelated barriers (e.g., personal bond, emotional discomfort); (II) patient-related barriers (e.g., patient characteristics, diversity, language barriers); and (III) family-related barriers (e.g., differential belief in or acceptance of provided prognostic information) (29).

With regard to physician-related barriers, multiple studies have examined the reasons behind this ellipsis of detailed communication about disease prognosis and care at the end of life by physicians. For example, Lamont showed that, even when patients request information about their 
Table 1 List of studies investigated in this narrative review

\begin{tabular}{|c|c|c|c|c|c|c|c|}
\hline Study & Author & Title & $\begin{array}{l}\text { Country/region } \\
\text { of origin }\end{array}$ & Sampling & Sample size & Research design & Key findings \\
\hline 1 & P. S. Craft, et al. & $\begin{array}{l}\text { Knowledge of treatment intent among patients with } \\
\text { advanced cancer: a longitudinal study }\end{array}$ & Australia & Single cohort of advanced cancer patients & 181 patients & Longitudinal study & Excessive optimism may lead to impaired decision making \\
\hline 2 & $\begin{array}{l}\text { Paul R. Helft, } \\
\text { et al. }\end{array}$ & $\begin{array}{l}\text { Oncology nurses' attitudes toward prognosis-related } \\
\text { communication: a pilot mailed survey of oncology } \\
\text { nursing society members }\end{array}$ & USA & Pilot mailed survey for nurses & 394 participatns & Cross-sectional study & $\begin{array}{l}\text { Respondents identified uncertainties regarding the scope of oncology nurses' role } \\
\text { in prognosis-related communication. Respondents also identified opportunities for } \\
\text { improved interdisciplinary communication }\end{array}$ \\
\hline 3 & $\begin{array}{l}\text { Baohui Zhang, } \\
\text { et al. }\end{array}$ & $\begin{array}{l}\text { Health care costs in the last week of life: associations } \\
\text { with end of life conversations }\end{array}$ & USA & Single cohort of advanced cancer patients & 627 patients & Longitudinal, multi-institutional study & $\begin{array}{l}\text { Advanced cancer patients who reported EOL conversations with physicians had } \\
\text { significantly lower health care costs in their final week of life }\end{array}$ \\
\hline 4 & $\begin{array}{l}\text { Emanuel Ezekiel } \\
\text { J., et al. }\end{array}$ & $\begin{array}{l}\text { Managed care, hospice use, site of death, and medical } \\
\text { expenditures in the last year of life }\end{array}$ & USA & Medicare data & $\begin{array}{l}65,618 \text { medicare } \\
\text { beneficiaries }\end{array}$ & Cross-sectional study & Patients with cancer using hospice did have significant savings \\
\hline 5 & $\begin{array}{l}\text { C. G. Koedoot, } \\
\text { et al. }\end{array}$ & $\begin{array}{l}\text { The content and amount of information given by } \\
\text { medical oncologists when telling patients with } \\
\text { advanced cancer what their treatment options are. } \\
\text { palliative chemotherapy and watchful-waiting }\end{array}$ & Netherlands & Single cohort incurable cancer patients & 95 patients & Prospective study & $\begin{array}{l}\text { Most of the physicians' attention is spent on the 'active' treatment option. Older } \\
\text { patients, married patients and patients in academic hospitals receive more information }\end{array}$ \\
\hline 6 & $\begin{array}{l}\text { Alfred F. Connors } \\
\mathrm{Jr} \text {, et al. }\end{array}$ & $\begin{array}{l}\text { A controlled trial to improve care for seriously III } \\
\text { hospitalized patients. The Study to Understand } \\
\text { Prognoses and Preferences for Outcomes and Risks of } \\
\text { Treatments (SUPPORT) }\end{array}$ & USA & $\begin{array}{l}\text { A 2-year prospective observational study (phase } \\
\text { I) followed by a 2-year controlled clinical trial } \\
\text { (phase II) }\end{array}$ & $\begin{array}{l}\text { Phase I: } 4,301 ; \\
\text { phase II: } 4,804\end{array}$ & $\begin{array}{l}\text { Patients and their physicians randomized } \\
\text { by specialty group to the intervention } \\
\text { group }(n=2,652) \text { or cotrol group }(n=2,152)\end{array}$ & $\begin{array}{l}\text { The phase I observation of SUPPORT confirmed substantial shortcomings in care } \\
\text { for seriously ill hospitalized adults. The phase II intervention failed to improve care or } \\
\text { patient outcomes }\end{array}$ \\
\hline 7 & $\begin{array}{l}\text { Murphy D. J., } \\
\text { et al. }\end{array}$ & $\begin{array}{l}\text { The influence of the probability of survival on patients' } \\
\text { preferences regarding cardiopulmonary resuscitation }\end{array}$ & USA & $\begin{array}{l}\text { Ambulatory patients in one geriatrics practice in } \\
\text { Denver, CO }\end{array}$ & 371 patients & Interview questions & $\begin{array}{l}\text { Most do not want to undergo CPR once a clinician explains the probability of survival } \\
\text { after the procedure }\end{array}$ \\
\hline 8 & $\begin{array}{l}\text { Amy M. Sullivan, } \\
\text { et al. }\end{array}$ & $\begin{array}{l}\text { Diagnosing and discussing imminent death in the } \\
\text { hospital: a secondary analysis of physician interviews }\end{array}$ & USA & $\begin{array}{l}\text { Physicians on the medical teams caring for } 70 \\
\text { patients who died in the hospital }\end{array}$ & 196 physicians & $\begin{array}{l}\text { Secondary exploratory analysis of } \\
\text { interviews with physicians }\end{array}$ & $\begin{array}{l}\text { Because more than two thirds of patients were unconscious or in and out of lucidity } \\
\text { in the last few days of life, waiting for certainty about prognosis may leave little } \\
\text { opportunity to help patients and their families prepare for death }\end{array}$ \\
\hline 9 & $\begin{array}{l}\text { David Casarett, } \\
\text { et al. }\end{array}$ & $\begin{array}{l}\text { How should clinicians describe hospice to patients and } \\
\text { families? }\end{array}$ & USA & Three Medicare-certified hospice organizations & $\begin{array}{l}100 \text { family members } \\
\text { of } 100 \text { patients who } \\
\text { died in hospice }\end{array}$ & Cross-sectional interviews & $\begin{array}{l}\text { By providing more information about hospice earlier in the illness course, clinicians } \\
\text { may be able to facilitate more-informed and more-timely decisions about hospice } \\
\text { enrollment }\end{array}$ \\
\hline 10 & Jenkins V., et al. & $\begin{array}{l}\text { What oncologists believe they said and what patients } \\
\text { believe they heard: an analysis of phase I trial } \\
\text { discussions }\end{array}$ & UK & $\begin{array}{l}\text { Oncologists and patients from } 5 \text { United Kingdom } \\
\text { cancer centers }\end{array}$ & $\begin{array}{l}17 \text { oncologists and } \\
52 \text { patients }\end{array}$ & $\begin{array}{l}\text { Following each consultation, clinicians } \\
\text { completed questionnaires. Patients and } \\
\text { oncologists also completed the Life } \\
\text { Orientation Test-Revised Questionnaire }\end{array}$ & $\begin{array}{l}\text { fundamental components of communication and information sharing about phase I } \\
\text { trial participation are often missing from interviews }\end{array}$ \\
\hline 11 & $\begin{array}{l}\text { Robinson T. M., } \\
\text { et al. }\end{array}$ & $\begin{array}{l}\text { Patient-oncologist communication in advanced cancer: } \\
\text { predictors of patient perception of prognosis }\end{array}$ & USA & $\begin{array}{l}\text { Analyzed audiorecorded encounters between } \\
\text { oncologists and advanced cancer patients }\end{array}$ & $\begin{array}{l}51 \text { oncologists } \\
\text { and } 141 \text { advanced } \\
\text { cancer patients }\end{array}$ & $\begin{array}{l}\text { Encounters were coded for communication } \\
\text { factors that might influence oncologist- } \\
\text { patient concordance }\end{array}$ & $\begin{array}{l}\text { Communication of pessimistic information to patients with advanced cancer increases } \\
\text { the likelihood that patients will report concordant prognostic estimates }\end{array}$ \\
\hline 12 & $\begin{array}{l}\text { Mary M. Step, } \\
\text { et al. }\end{array}$ & $\begin{array}{l}\text { Patient perceptions of oncologist-patient } \\
\text { communication about prognosis: changes from initial } \\
\text { diagnosis to cancer recurrence }\end{array}$ & USA & $\begin{array}{l}\text { Female patients being treated for a cancer } \\
\text { recurrence at a comprehensive cancer center }\end{array}$ & 30 female patients & A thematic analysis of patient interviews & $\begin{array}{l}\text { Problematic integration theory is offered as an important explanatory mechanism for } \\
\text { understanding oncologist-patient communication about prognosis during a cancer } \\
\text { recurrence }\end{array}$ \\
\hline 13 & $\begin{array}{l}\text { Jane C. Weeks, } \\
\text { et al. }\end{array}$ & $\begin{array}{l}\text { Patients' expectations about effects of chemotherapy } \\
\text { for advanced cancer }\end{array}$ & USA & $\begin{array}{l}\text { Patients who were alive } 4 \text { months after diagnosis } \\
\text { and received chemotherapy for newly diagnosed } \\
\text { metastatic (stage IV) lung or colorectal cancer }\end{array}$ & 1,193 patients & Patient surveys & $\begin{array}{l}\text { Many patients receiving chemotherapy for incurable cancers may not understand that } \\
\text { chemotherapy is unlikely to be curative }\end{array}$ \\
\hline 14 & $\begin{array}{l}\text { Yennurajalingam } \\
\text { S., et al. }\end{array}$ & $\begin{array}{l}\text { Perception of curability among advanced cancer } \\
\text { patients: an international collaborative study }\end{array}$ & International & $\begin{array}{l}\text { Advanced cancer patients receiving palliative } \\
\text { care from } 11 \text { countries across the world }\end{array}$ & 1,390 patients & $\begin{array}{l}\text { Patients surveyed using a patient illness } \\
\text { understanding survey and control } \\
\text { preference scale }\end{array}$ & Inaccurate perception of curability in advanced cancer patients is $55 \%$ \\
\hline 15 & $\begin{array}{l}\text { El-Jawahri A., } \\
\text { et al. }\end{array}$ & $\begin{array}{l}\text { Associations among prognostic understanding, quality } \\
\text { of life, and mood in patients with advanced cancer }\end{array}$ & USA & $\begin{array}{l}\text { Within } 6 \text { to } 12 \text { weeks of initiating chemotherapy } \\
\text { for advanced gastrointestinal cancers }\end{array}$ & 62 patients & $\begin{array}{l}\text { A 13-item questionnaire was used to } \\
\text { assess patients' information preferences, } \\
\text { perceptions of their prognosis }\end{array}$ & $\begin{array}{l}\text { Although patients desired detailed information about their illlness, half incorrectly } \\
\text { perceived their cancer as curable }\end{array}$ \\
\hline
\end{tabular}

Table 1 (continued) 
Table 1 (continued)

Study Author

Country/reg
of origin

Sample size

Research design

Key findings

J. C. Weeks,
et al.

Jennifer $W$. eir treatment preferences

USA

Terminally ill cancer patients at five teaching hospitals in the United States care consistent with preferences

18 G. Silvestri, et al. Preferences for chemotherapy in patients with Preferences for chemotherapy in patients with
advanced non-small cell lung cancer: descriptive study
based on scripted interviews

19 Tsang-Wu Liu, Terminally ill taiwanese cancer patients' and family Taiwan caregivers agreement on pattens or tre sustaining

20 Joshua J Fenton, Impact of prognostic discussions on the patientphysician relationship: prospective cohort study

Paul R. Helft, Associations among awareness of prognosis, et al. hopefulness, and coping in patients with advanced cancer participating in phase I clinical trials

22 Thomas J. Smith, Giving honest information to patients with advanced USA et al. cancer maintains hope

23 Gunilla Lundquist Information of imminent death or not: does it make a Swede et al.

24 Young Ho Yun, Impact of awareness of terminal illness and use of Korea palliative care or ins onsive care unit on the survival of

25 Lamont E. B., Prognostic disclosure to patients with cancer near the USA etal. end of life

26 W. Söllner, et al. How successful are oncologists in identifying patient Austria distress, perceived social support, and need for psychosocial counselling?

27 Steven D. Passik, Use of a depression screening tool and a fluoxetine- USA et al. based algorithm to improve the recognition and demonstration project

28 D. L. Roter, et al. Improving physicians' interviewing skills and reducing USA patients' emotional distress. A randomized clinical tria

29 S. Ford, et al. Can oncologists detect distress in their out-patients and UK how satisfied are they with their performance during bad news consultations?
Patients with advanced cancer 325 patients

Patients previously treated with platinum based 81 patients chemotherapy for advanced NSCLC

Terminally ill Taiwanese cancer patients' and sectional studies in 2003-2004 and 2011-2012

1,049 and

Patients with advanced cancer

265 patients

Longitudinal cohort study

Structured, face-to-face interviews

d cancer participating in 179 patients phase I clinical trials

Advanced cancer who were facing firstsecond-, third-, and fourth-line chemotherapy

All cancer deaths between 2006 and $2008 \mathrm{for}$ which the patient did not lose his or her decisionmaking capacities

Cancer patients who were determined by

Measured hope using the Herth Hope Index

13,818 patients

619 patients

Five hospices in Chicago, Illinois

326 patients with Prospective cohort study

Cancer patients undergoing radiotherapy

Ambulatory oncology patients who were screened with the Zung Self-rating Depression Scale (ZSDS)

Patients with emotional distress

Newly referred out-patients who were receiving 5 oncologists bad news

Data was taken from a national quality register for end-of-life care. Nonparam methods were used for statistical analyse

Prospective cohort study at 11 university hospitals using questionnaires

Distress, perceived social support and desire for supportive counselling were desire for supportie counsenting were Structured follow-up interviews by their oncologist determined whether the patients qualified for a diagnosis of a major

Randomized, controlled field tria

Self-report measures of the oncologists' satisfaction with their performance during Patients with metastatic colon and lung cancer overestimate their survival probabit
and these estimates may influence their preferences about medical therapies

Patients with cancer are more likely to receive EOL care that is consistent with their preferences when they have had the opportunity to discuss their wishes for $\mathrm{EOL}$ care with a physician

Many would not choose chemotherapy for its likely survival benefit of 3 months but would if it improved quality of life

Patients and family caregivers had poor-to-fair agreement on LST-preference patterns And agreement declined significantly over a decade

Prognostic discussion is not intrinsically harmful to the patient-physician relationship Having a more accurate view of prognosis in the face of terminal illness was associated with reduced hopefulness, which may be related to a poorer sense of coping

Hope is maintained when patients with advanced cancer are given truthful prognostic and treatment information, even when the news is bad Providing information of imminent death to a patient with cancer at the end of life does care and to increase the likelihood of fulfiling the principles of a good death

Patients' being aware that they are dying and entering a palliative care facility or ICU does not seem to influence patients' survival

Physicians reported that even if patients with cancer requested survival estimates, they would provide a frank estimate only $37 \%$ of the time

Oncologists' recommendations for supportive counselling did not correlate with patien thess or the amount of perceived support but rather with progressive disease and

Oncologists can be empowered to recognize and treat depression in their patients with a screen-and-intervene approach Important changes in physicians' communication skills were evident after an 8-hour program

the bad news interviews

Table 1 (continued)

The ability to detect distress varied between each clinician and confirmed the chestusions of past studies that oncologists would benefit from up-grading the 
Table 1 (continued)

Study Author

Title $\quad \begin{aligned} & \text { Country/region } \\ & \text { of origin }\end{aligned}$

Sampling

Sample size

Research design

Key findings

$\begin{array}{lll}\text { Verna } L & \begin{array}{l}\text { Evaluation of physician and nurse dyad training } \\ \text { Hendricks- }\end{array} \\ & \text { procedures to deliver a palliative and end-of-life }\end{array}$

USA

Evaluation of training procedures used to prepare 5 pediatric neurooncologists and 8
pediatric nurses

Evaluations included dichotomous ratings communication interventon to parents of children with a brain tumor

31 B. J. Hammes, Death and end-of-life planning in one midwestern et al. community

32 A. M. Cugliari, Use of a videotape for educating patients about et al. advance directives

33 J. J. Fins, et al. End-of-life decision-making in the hospital: current MD/RN dyads to deliver an intervention qualtative comments on content,

All adult decedents residing in areas within 5 ZIP 540 decedents codes

for interviews an advance directive to enhance patient

control over treatment decisions
The MDs and RNs r helpful and useful

Data were collected from medical records Advance planning can be prevalent and can effectively guide end-of-life decisions and death certificates. Treating physicians and decedent proxies were also contacted

An 18-minute educational videotape about Videotapes may not increase completion of advance directives, but they may be usefu the usefulness of a health care proxy as as a component of multi-faceted efforts to promote advance directives

Outcome measures were identification Findings suggest opportunities and challenges for improving practice patterns for

hospitalized dying patients

EOL, end-of-life; CPR, cardiopulmonary resuscitation; NSCLC, non-small cell lung cancer; LST, life-sustaining treatment; ICU, intensive care unit; PC/EOL, palliative and end-of-life care; DNR, do-not-resuscitate. 
prognosis specifically, physicians only offer an estimate $37 \%$ of the time (30). In other studies, oncologists express concern about having their patients view them less favorably if they share detailed information about prognosis, or that such information would make patients feel needlessly hopeless or upset $(22,31)$. Despite these concerns, multiple studies document that patients with life-ending disease do not lose hope, suffer, or die earlier as a result of end-of-life conversations (32-34).

Other reasons physicians may avoid these discussions include the perception that such discussions are time consuming, or the fear that physicians will be held accountable for an inaccurate estimate. Although less well described and documented in the literature, we suggest that physician's personal skills and comfort with managing patients' reactions to hearing negative or bad news is a central impediment to prognosis-related communication, as physicians fear triggering strong emotional responses with patients, and/or may feel ill-equipped to manage the emotional reactions (35).

The large body of evidence we have partially reviewed here suggests that approximately one-third of oncologists avoid or rarely engage in prognosis related discussions and/ or lack the skills they need in this area. We suggest that patients of these oncologists may thereby receive lower quality prognosis-related communication, have fewer opportunities to understand and accept their prognosis, which in turn contributes to preferences for over-treatment at or near the end of life.

Some of the barriers that lead to this avoidance of such communication can be generalized to all interpersonal interactions. Maynard's work on the communication of bad news suggests that there is a social norm that marks the action of delivering bad news as a "dis-preferred" social action (36). Such models may help contextualize why doctors avoid or delay communicating bad news or attempt to qualify or mitigate the news.

Studies also suggest that, because of their own anxiety, physicians tend to avoid discussing the emotional and social impact of patients' problems. This negative emotional feedback to patients' distress has been found to negatively affect physicians themselves emotionally and, in turn, tends to elevate patients' distress (35). In summary, the fear of not being able to appropriately handle patients' acute distress, and/or that disclosure of negative information will have a detrimental effect on the doctor-patient relationship are major factors in physicians' reluctance to discuss negative news such as prognosis.
Lastly, oncologists may perceive that an accurate communication of a poor prognosis can affect hopefulness negatively. A 2003 study examined the effects of hopefulness on accurate prognostic understanding. A total of 179 patients enrolled in a phase I study were interviewed using items from the Functional Assessment of Cancer Therapy-General instrument (FACT-G). The study found that hopefulness and coping were positively correlated, whereas hopefulness was negatively associated with accurate prognostic understanding (37). Furthermore, $84 \%$ of patients in this study had an overly optimistic estimate of their prognosis, with more educated patients demonstrating a more realistic awareness of prognosis and female respondents reporting more realistic estimation of their prognosis than males (37).

\section{Suggestions to improve prognosis related communication with advanced cancer patients}

A review of the literature and personal experience suggest that physicians are not equal in their ability to engage in high quality prognosis-related communication with advanced cancer patients. Many factors contribute to these differences in oncologists' ability and willingness to handle these conversations, such as how comfortable they feel managing the emotional reactions that ensue. Several studies have examined different methods to improve physicians' communications skills. There are multiple programs that focus on communication skills for healthcare providers. The simplest of these consist of online videos that can be watched while the viewer can observe a virtual conversation between a skilled healthcare provider and a sick patient in order to observe high quality examples of how to approach these patients. Healthcare workers can use these maneuvers or phrases in certain situations for breaking bad news, discussing prognosis or referring to hospice.

More complicated forms of communication skills training involve interactive live courses, where participants can first observe how these stressful conversations are handled, then take turns participating in role play, ending by receiving feedback from expert trainers. Such courses can last for few days and they usually cover multiple situations, starting from breaking bad news to discussing prognosis and to making referrals to hospice, and ending in teaching how to approach an actively dying patient.

One systematic review suggested that communication skills courses may benefit cancer care professionals (38). 
This review concluded that programs for communication skills training are useful for healthcare professionals who work in cancer care, and lead to increased satisfaction among health care professionals by improving communication skills, knowledge and confidence, along with changes in attitudes. On the other hand, the review found no evidence that skills training can improve the ability to detect patients' distress. Furthermore, the evidence that physicians who are not skilled at baseline can improve with skills training interventions is mixed, and it is not clear if those interventions are really helpful for physicians who may intrinsically lack this type of "emotional intelligence" (39-41).

Overall, the goal of these courses is to make providers more comfortable in initiating difficult conversations related to discussing prognosis and end of life care. So skills training may improve the quality of end-of-life communication with advanced cancer patients, although evidence of the effectiveness of such skills training on diverse groups or at longer time from training is lacking. However, it is reasonable to assume that, to the extent that communication skills training can improve the quality of clinicians' communication skills, it will also contribute to better understanding of prognosis-related information and provide a framework for appropriate patient-centered decision making.

\section{Different approaches for differently-skilled oncologists}

As we consider approaches to improving end of life communication for cancer patients, and based on the broad review presented above, we believe that it is both valid and useful to group oncologists into three broad categories with regard to their ability to engage in high quality communication with their advanced cancer patients. We base these categories roughly on data we have reviewed above regarding evidence for variable skills among clinicians: highly skilled, moderately skilled, and lower skilled. The utility of this grouping is that it allows us to consider different approaches for improving end of life communication with advanced cancer patients for each group.

Highly skilled oncologists who already possess high quality communication skills may only need operational support to help them continue their performance at this high level. Examples of this kind of support include models for practicing that reward time spent engaging in end-oflife care planning and establishing goal of care at the end of life. Furthermore, highly skilled physicians could serve as teachers, mentors, or reviewers for their colleagues. They might also be an appropriate group for "train the trainers" type workshops when seeking skills training facilitators.

We theorize that moderately skilled oncologists are the group that would benefit the most from targeted skills training programs, where multiple high-quality examples have already been conducted (e.g., OncoTalk) (42). To our knowledge, studies of the outcomes of such communications skills training programs have not stratified or controlled for communication skills levels of oncologists participating in the programs in the ways we have suggested. We believe that those with moderate skills who already have a foundation of communication skills are the group most likely to benefit from skills training courses. This hypothesis is worthy of future study in research examining the impact of these courses.

For the less skilled group, research about teaching physicians to "read" emotional cues from patients suggests that lower-skilled physicians are less likely to gain benefit from training programs (43). As we discussed earlier in this review, there are some physician-related factors that may be difficult to overcome since they may be intrinsic to some physicians' personality and social functioning. For this group of physicians, attempts to enhance end of life and prognosis-related communication could focus on supporting lower skilled oncologists with resources outside of their own direct communication. Examples of some of these interventions could include matching physicians with skilled nurses in oncology communication (44). Such a model, which has been tested in some research settings (45), can offer great support to oncologists who are either less-skilled or who lack a desire to alter their personal communication styles. Limitations to this model include that nursing or other staff may not have the same level of knowledge or experience that the oncologist has to feel confident about handling these conversations or offering prognostic information. Other limitations include the issue of scope of practice, about which oncology nurses have voiced a concern in previous studies (3). Another limitation is that physicians may not be open to allowing other colleagues to discuss prognosis with their patients, or may be reluctant to allow for the possibility that less optimistic messages might be conveyed to their patients. This has been true in our anecdotal experience, and represents a challenging organizational issue.

A second model to help the lower skilled group of oncologists would be to facilitate referrals to palliative care 
and hospice consultation teams (46), either automatically or triggered by measures such as responses to the "Would you be surprised?" question (47-49). Palliative care referrals have been shown to have positive outcomes on the quality of end of life care for advanced cancer patients, and much of this effect is likely due to its effects on improved communication, including having effective goals of care conversations $(50,51)$. The limitations of this model include that some patients may be reluctant to accept referral to palliative care or hospice teams, or they may reject prognostic messages that are less optimistic than those presented by their primary oncologist. Some patients may have pre-existing assumptions about these services from previous experiences.

Other options to help this lower skilled group of oncologists include pre-hospice and care management programs (52), advance directives completion efforts, in addition to developing models to expose patients to trained individuals who can provide structured end-oflife discussions, such as those found in Respecting Choices (53-56), and other advanced illness coordinated care programs (57). Each of these programs, when implemented, has demonstrated some effectiveness in improving communication and decision making at or near the end of life.

\section{Conclusions}

High quality prognosis-related communication is a critical component of advance care planning for cancer patients, and may play the single most important role of any of the complex but modifiable factors that affect end of life care decisions. Better prognosis-related communication is a key factor to enhance and enrich patient's comprehension of their prognosis and goals of therapy, and may contribute to lower uptake of overtreatment and utilization of healthcare resources at or near the end of life. Ideally, high quality communication also improves the attainment of goalsconcordant end of life care. Previous efforts to improve end of life communication have generally not taken into account widely varying communication skill and comfort levels among clinicians. Based on the evidence presented here, we believe that oncologists can be usefully divided into three groups with respect to their ability to engage in meaningful, high quality communication with their cancer patients. Highly skilled individuals need organizational support to continue their performance and may serve as mentors for others; moderately skilled oncologists may benefit from targeted skills training programs to improve their existing skills (e.g., OncoTalk); lower skilled oncologists may benefit from supportive programs that would supplement their primary medical care of their patients, instead of working on enhancing their ability to engage in effective communication directly. Oncologists who struggle with prognosis-related communication and managing patients' emotional reactions may benefit from programs of external support and partnerships that allow them to share these important interactions with other colleagues.

Our suggestion to group oncologists into these three categories is a conceptual framework and not a categorization based on objective tests or assessments. Measured outcomes of the quality of the dying experience for advanced cancer patients, when derived from providerspecific data, may aid in grouping oncologists within this framework. We hypothesize that this classification may help to guide efforts and resources needed to improve each group in differential ways.

\section{Acknowledgments}

Funding: None.

\section{Footnote}

Reporting Checklist: The authors have completed the Narrative Review reporting checklist. Available at https:// dx.doi.org/10.21037/apm-21-142

Conflicts of Interest: Both authors have completed the ICMJE uniform disclosure form (available at https://dx.doi. org/10.21037/apm-21-142). The authors have no conflicts of interest to declare.

Ethical Statement: The authors are accountable for all aspects of the work in ensuring that questions related to the accuracy or integrity of any part of the work are appropriately investigated and resolved.

Open Access Statement: This is an Open Access article distributed in accordance with the Creative Commons Attribution-NonCommercial-NoDerivs 4.0 International License (CC BY-NC-ND 4.0), which permits the noncommercial replication and distribution of the article with the strict proviso that no changes or edits are made and the original work is properly cited (including links to both the formal publication through the relevant DOI and the license). 
See: https://creativecommons.org/licenses/by-nc-nd/4.0/.

\section{References}

1. Craft PS, Burns CM, Smith WT, et al. Knowledge of treatment intent among patients with advanced cancer: a longitudinal study. Eur J Cancer Care (Engl) 2005;14:417-25.

2. Applebaum AJ, Kolva EA, Kulikowski JR, et al. Conceptualizing prognostic awareness in advanced cancer: a systematic review. J Health Psychol 2014;19:1103-19.

3. Helft PR, Chamness A, Terry C, et al. Oncology nurses' attitudes toward prognosis-related communication: a pilot mailed survey of oncology nursing society members. Oncol Nurs Forum 2011;38:468-74.

4. Miller KD, Nogueira L, Mariotto AB, et al. Cancer treatment and survivorship statistics, 2019. CA Cancer J Clin 2019;69:363-85.

5. Zhang B, Wright AA, Huskamp HA, et al. Health care costs in the last week of life: associations with end-of-life conversations. Arch Intern Med 2009;169:480-8.

6. Emanuel EJ, Ash A, Yu W, et al. Managed care, hospice use, site of death, and medical expenditures in the last year of life. Arch Intern Med 2002;162:1722-8.

7. Jacobson M, O'Malley AJ, Earle CC, et al. Does reimbursement influence chemotherapy treatment for cancer patients? Health Aff (Millwood) 2006;25:437-43.

8. Rangachari D, Smith TJ. Integrating palliative care in oncology: the oncologist as a primary palliative care provider. Cancer J 2013;19:373-8.

9. Smith TJ, Temin S, Alesi ER, et al. American Society of Clinical Oncology provisional clinical opinion: the integration of palliative care into standard oncology care. J Clin Oncol 2012;30:880-7.

10. Levy MH, Back A, Benedetti C, et al. NCCN clinical practice guidelines in oncology: palliative care. J Natl Compr Canc Netw 2009;7:436-73.

11. Tang ST, Liu TW, Chow JM, et al. Associations between accurate prognostic understanding and end-of-life care preferences and its correlates among Taiwanese terminally ill cancer patients surveyed in 2011-2012. Psychooncology 2014;23:780-7.

12. The Medicare Payment Advisory Commission (MedPAC) 2019 report to the Congress. Available online: http:// medpac.gov/docs/default-source/reports/jun19_ medpac_reporttocongress_sec.pdf

13. Back AL, Anderson WG, Bunch L, et al.

Communication about cancer near the end of life.
Cancer 2008;113:1897-910.

14. A controlled trial to improve care for seriously ill hospitalized patients. The study to understand prognoses and preferences for outcomes and risks of treatments (SUPPORT). The SUPPORT Principal Investigators. JAMA 1995;274:1591-8.

15. Murphy DJ, Burrows D, Santilli S, et al. The influence of the probability of survival on patients' preferences regarding cardiopulmonary resuscitation. $\mathrm{N}$ Engl J Med 1994;330:545-9.

16. Koedoot CG, Oort FJ, de Haan RJ, et al. The content and amount of information given by medical oncologists when telling patients with advanced cancer what their treatment options are. palliative chemotherapy and watchful-waiting. Eur J Cancer 2004;40:225-35.

17. Sullivan AM, Lakoma MD, Matsuyama RK, et al. Diagnosing and discussing imminent death in the hospital: a secondary analysis of physician interviews. J Palliat Med 2007;10:882-93.

18. Casarett DJ, Crowley RL, Hirschman KB. How should clinicians describe hospice to patients and families? J Am Geriatr Soc 2004;52:1923-8.

19. Jenkins V, Solis-Trapala I, Langridge C, et al. What oncologists believe they said and what patients believe they heard: an analysis of phase I trial discussions. J Clin Oncol 2011;29:61-8.

20. Robinson TM, Alexander SC, Hays M, et al. Patientoncologist communication in advanced cancer: predictors of patient perception of prognosis. Support Care Cancer 2008;16:1049-57.

21. Step MM, Ray EB. Patient perceptions of oncologistpatient communication about prognosis: changes from initial diagnosis to cancer recurrence. Health Commun 2011;26:48-58.

22. Weeks JC, Catalano PJ, Cronin A, et al. Patients' expectations about effects of chemotherapy for advanced cancer. N Engl J Med 2012;367:1616-25.

23. Yennurajalingam S, Rodrigues LF, Shamieh O, et al. Perception of curability among advanced cancer patients: an international collaborative study. Oncologist 2018;23:501-6.

24. El-Jawahri A, Traeger L, Park ER, et al. Associations among prognostic understanding, quality of life, and mood in patients with advanced cancer. Cancer 2014;120:278-85.

25. Weeks JC, Cook EF, O'Day SJ, et al. Relationship between cancer patients' predictions of prognosis and their treatment preferences. JAMA 1998;279:1709-14.

26. Mack JW, Weeks JC, Wright AA, et al. End-of-life 
discussions, goal attainment, and distress at the end of life: predictors and outcomes of receipt of care consistent with preferences. J Clin Oncol 2010;28:1203-8.

27. Silvestri G, Pritchard R, Welch HG. Preferences for chemotherapy in patients with advanced non-small cell lung cancer: descriptive study based on scripted interviews. BMJ 1998;317:771-5.

28. Liu TW, Wen FH, Wang CH, et al. Terminally ill taiwanese cancer patients' and family caregivers' agreement on patterns of life-sustaining treatment preferences is poor to fair and declines over a decade: results from two independent cross-sectional studies. J Pain Symptom Manage 2017;54:35-45.e4.

29. Horlait M, Chambaere K, Pardon K, et al. What are the barriers faced by medical oncologists in initiating discussion of palliative care? A qualitative study in Flanders, Belgium. Support Care Cancer 2016;24:3873-81.

30. Lamont EB, Christakis NA. Prognostic disclosure to patients with cancer near the end of life. Ann Intern Med 2001;134:1096-105.

31. Fenton JJ, Duberstein PR, Kravitz RL, et al. Impact of prognostic discussions on the patient-physician relationship: prospective cohort study. J Clin Oncol 2018;36:225-30.

32. Smith TJ, Dow LA, Virago E, et al. Giving honest information to patients with advanced cancer maintains hope. Oncology (Williston Park) 2010;24:521-5.

33. Lundquist $\mathrm{G}$, Rasmussen $\mathrm{BH}$, Axelsson B. Information of imminent death or not: does it make a difference? J Clin Oncol 2011;29:3927-31.

34. Yun YH, Lee MK, Kim SY, et al. Impact of awareness of terminal illness and use of palliative care or intensive care unit on the survival of terminally ill patients with cancer: prospective cohort study. J Clin Oncol 2011;29:2474-80.

35. Ha JF, Longnecker N. Doctor-patient communication: a review. Ochsner J 2010;10:38-43.

36. Cicourel A. Bad news, good news: conversational order in everyday talk and clinical settings. Language in Society, 2005;34:282-91.

37. Helft PR, Hlubocky F, Wen M, et al. Associations among awareness of prognosis, hopefulness, and coping in patients with advanced cancer participating in phase I clinical trials. Support Care Cancer 2003;11:644-51.

38. Merckaert I, Libert Y, Razavi D. Communication skills training in cancer care: where are we and where are we going? Curr Opin Oncol 2005;17:319-30.

39. Söllner W, DeVries A, Steixner E, et al. How successful are oncologists in identifying patient distress, perceived social support, and need for psychosocial counselling? Br J Cancer 2001;84:179-85.

40. Passik SD, Donaghy KB, Theobald DE, et al. Oncology staff recognition of depressive symptoms on videotaped interviews of depressed cancer patients: implications for designing a training program. J Pain Symptom Manage 2000;19:329-38.

41. Roter DL, Hall JA, Kern DE, et al. Improving physicians' interviewing skills and reducing patients' emotional distress. A randomized clinical trial. Arch Intern Med 1995; 155:1877-84.

42. Back AL, Arnold RM, Tulsky JA, et al. Teaching communication skills to medical oncology fellows. J Clin Oncol 2003;21:2433-6.

43. Ford S, Fallowfield L, Lewis S. Can oncologists detect distress in their out-patients and how satisfied are they with their performance during bad news consultations? $\mathrm{Br}$ J Cancer 1994;70:767-70.

44. Hendricks-Ferguson VL, Kane JR, Pradhan KR, et al. Evaluation of physician and nurse dyad training procedures to deliver a palliative and end-of-life communication intervention to parents of children with a brain tumor. J Pediatr Oncol Nurs 2015;32:337-47.

45. Hendricks-Ferguson VL, Pradhan K, Shih CS, et al. Pilot evaluation of a palliative and end-of-life communication intervention for parents of children with a brain tumor. J Pediatr Oncol Nurs 2017;34:203-13.

46. Dunlop RJ, Hockley JM. Hospital-based palliative care teams: the hospital-hospice interface. New York: Oxford University Press, 1998.

47. Moss AH, Ganjoo J, Sharma S, et al. Utility of the "surprise" question to identify dialysis patients with high mortality. Clin J Am Soc Nephrol 2008;3:1379-84.

48. Da Silva Gane M, Braun A, Stott D, et al. How robust is the 'surprise question' in predicting short-term mortality risk in haemodialysis patients? Nephron Clin Pract 2013;123:185-93.

49. Thomas K, Free A. The gold standards framework prognostic indicator guidance. Center for End of Life Care Shrewsbury (UK), 2011.

50. Temel JS, Greer JA, Muzikansky A, et al. Early palliative care for patients with metastatic non-small-cell lung cancer. N Engl J Med 2010;363:733-42.

51. Parikh RB, Kirch RA, Smith TJ, et al. Early specialty palliative care--translating data in oncology into practice. N Engl J Med 2013;369:2347-51.

52. Connor SR. New initiatives transforming hospice care. 
Hosp J 1999;14:193-203.

53. Pearlman RA, Cole WG, Patrick DL, et al. Advance care planning: eliciting patient preferences for life-sustaining treatment. Patient Educ Couns 1995;26:353-61.

54. Hammes BJ, Rooney BL. Death and end-of-life planning in one midwestern community. Arch Intern Med 1998;158:383-90.

55. Cugliari A, Sobal J, Miller T. Use of a videotape for educating patients about advance directives. Am J Health

Cite this article as: Al-Issa K, Helft PR. Narrative review of prognosis related communication in advanced cancer patients. Ann Palliat Med 2021;10(8):9239-9250. doi: 10.21037/apm-21142
Behav 1999;23:105-14.

56. Fins JJ, Miller FG, Acres CA, et al. End-of-life decisionmaking in the hospital: current practice and future prospects. J Pain Symptom Manage 1999;17:6-15.

57. Bateman WB, Kramer EJ, Glassman KS. editors. Patient and family education in managed care and beyond: Seizing the teachable moment. New York: Springer Publishing Company, 1999. 